\title{
Artificial Intelligence in Communication Management: A Cross-National Study on Adoption and Knowledge, Impact, Challenges, and Risks
}

\begin{abstract}
Purpose - Artificial intelligence ( $\mathrm{Al}$ ) might change the communications profession immensely, but the academic discourse is lacking an investigation of the perspective of practitioners on this. The article addresses this research gap. It offers a literature overview and reports about an empirical study on Al in communications, presenting first insights on how professionals in the field assess the technology.
\end{abstract}

Design/methodology/approach - A quantitative cross-national study among 2,689 European communication practitioners investigated four research questions: RQ1 - How much do professionals know about Al and to what extent are they already using Al technologies in their everyday lives? RQ2 - How do professionals rate the impact of Al on communication management? RQ3 - Which challenges do professionals identify for implementing $\mathrm{Al}$ in communication management? RQ4 - Which risks do they perceive?

Findings - Communication professionals revealed a limited understanding of artificial intelligence, and expected the technology to impact the profession as a whole more than the way their organisations or themselves work. Lack of individual competencies, and organisations struggling with different levels of competency and unclear responsibilities were identified as key challenges and risks.

Implications - The results highlight the need for communication managers to educate themselves and their teams about the technology, and to identify the implementation of artificial intelligence as a leadership issue.

Originality/value - The article offers the first cross-national quantitative study on artificial intelligence in communication management. It presents valuable empirical insights on a trending topic in the discipline, highly relevant for both academics and practitioners.

Keywords - Artificial intelligence, Al, technology, communication management, strategic communication, public relations, marketing, corporate communications.

Paper type - Research paper. 


\section{Introduction}

Artificial intelligence ( $\mathrm{Al}$ ) is becoming commonplace not only in the retail, service, and manufacturing industry but also as part of everyday life. Language-based assistants like Apple Siri or Amazon Alexa and algorithms used on news sites and e-commerce platforms are a reality today. The Al Index 2018 Report published by Stanford University identified increasing numbers of patents on Al technologies, more and more job openings that demand Al skills, and a rising favourable mass media coverage of Al related topics. The report also reveals that artificial intelligence continues to evolve as a trending field in academia, with rising numbers of conferences, course enrollments, and academic research on $\mathrm{Al}$ and its implications in different disciplines (Shoham et al., 2018).

It can be assumed that artificial intelligence will also impact the fields of communication management. Industry magazines and consultants already highlight a broad variety of possible $\mathrm{Al}$ applications in the field, ranging from analytics to targeting, from content creation to chatbots, and from evaluation routines to strategy development and crisis management - just to list a few (Foldes, 2018; Petrucci, 2018). The professional discourse frames Al technologies mostly as an addition to professional activities, emphasizing its opportunities but also claiming that humans "cannot be replaced or mimicked by technology" (Foldes, 2018).

A perspective of particular interest on this might be one that considers the experiences of the communication professionals themselves. How knowledgeable are they about artificial intelligence? To what extent have they already adapted to this technology? And how do they perceive the challenges and risks that Al might bring to the profession?

In this research article, we will conduct a literature review on artificial intelligence in communication management and present results of a quantitative study among 2,689 practitioners in Europe that addresses those questions.

\section{Theoretical background}

We follow a two-step approach to outline our theoretical background and to present the current state of research: First, we will unpack what we mean by artificial intelligence referring to literature in the field of business information and computer science literature. After that, we will introduce the concept of communication management and review research on artificial intelligence in this particular discipline. Combining both lines of thought will identify research gaps that are addressed in the empirical study.

\section{Defining artificial intelligence}

The term "artificial intelligence" can be tracked back to the mid-1950s, when the USAmerican computer scientist and Al pioneer John McCarthy used the label in a grant application for a conference. More than half a century of research has brought up a vast number of definitions. Russell and Norvig (2016) have identified four definitional strands along the dimensions thought processes/reasoning vs. behaviour and human performance vs. ideal performance. Nils John Nilsson from Stanford University, one of the founding researchers of the Al discipline, declares that artificial intelligence "is concerned with intelligent behavior in artifacts", which comprises "perception, reasoning, learning, communicating, and acting in complex environments" (Nilsson, 1998, p. 1). David Poole and Alan Mackworth from the department of computer science at the University of British Columbia, define Al as "computational agents that act intelligently" (Poole and Mackworth, 2017, p. 3). Intelligence, in their understanding, is characterised by adequate acting 
according to circumstances and goals, flexible adopting to changing environments and objectives, learning from experience, and appropriate decision-making.

More concretely, Tredinnick (2017) names "natural language processing" and "machine learning" as examples for the "cluster of technologies" artificial intelligence refers to (p. 37). Similarly, Schweyer (2018) lists predictive analytics and machine learning as "components of Al" (p. 3), and Kaplan and Haenlein (2018) claim that machine learning "is an essential part of $\mathrm{Al}$, but $\mathrm{Al}$ is broader than machine learning since it also covers a system's ability to perceive data (e.g., natural language processing or voice/image recognition)" ( $p$. 17). Elsewhere, machine learning is interpreted as a meta-concept that embraces subsets such as knowledge representation (Young, 2018).

Taking these different definitional approaches into account, artificial intelligence can, in our understanding, be described as

flexible decision-making processes and actions of software-driven agents. They adapt to changing goals and unpredictable situations, learn from experience, aim for rationality, but also carry on in spite of perceptual and computational limitations. $\mathrm{Al}$ is based on technologies like natural language processing, data retrieval and knowledge representation, semantic reasoning, and machine learning.

Due to combining several definitional strands, we are aware that different parts of the proposed definition address various dimensions of artificial intelligence. As mentioned, knowledge representation can be seen as a subset of machine learning, whereas actions of software-driven agents might be based on their situational surrounding or their past experiences (Rahwan et al., 2019, p. 483). However, including both abstract and concrete aspects of Al makes this definition both conceptually inclusive as well as easily understandable for practitioners outside the information technology profession.

\section{Artificial intelligence in communication management}

We define communication management as "the steering of all communications in the context of the organization" (Brønn, 2014, p. 753). Thus, we follow an integrated understanding of communications beyond disciplinary boundaries and we reviewed $\mathrm{Al}$ literature from both the fields of marketing communications and public relations.

In the first-mentioned discipline, several textbooks aiming at practitioners have been published within the last two years (e.g., Gentsch, 2019; King, 2019; Penn, 2017; Pradeep et al., 2019; Seligman, 2019; Sterne, 2017; Struhl, 2017), flanked by a handful of academic journal articles and working papers (e.g., Dawar and Bendle, 2018; Dimitrieska et al., 2018; Jordan, 2018; Kose and Sert, 2017; Wirth, 2018). The application of artificial intelligence in public relations has been discussed less intensively. Apart from reports in industry magazines, we were only able to identify a handful of articles and research papers published to this day (Collister, 2015; Galloway and Swiatek, 2018; Niederhäuser and Rosenberger, 2018; Valin, 2018; Waxman, 2018; Wiesenberg and Tench, 2020).

Most of this work presents the benefits that artificial intelligence might bring to communication management, and how the technology will reshape and redefine professional roles in the discipline. Dawar and Bendle (2018) outline scenarios how Al will impact marketing, and claim that "Al assistants will transform how companies connect with their customers" (p. 82). Accordingly, Dimitrieska, Stankovska and Efremova (2018) name optimizing messages, improving targeting, and using bots for customer communication as opportunities of Al based marketing. Galloway and Swiatek (2018) add social media activities 
and media monitoring to this list, while Kose and Sert (2017) describe several ways to implement artificial intelligence into content marketing.

Valin (2018) argues that 32 percent of all skills needed in communications involve zero tech support and 27 percent involve minor tech support; therefore, 59 percent of all skills will not be replaced by artificial intelligence and "humans [are] still needed" (p. 3). According to another source, communications professionals have only a 1.5 percent chance of losing their job to technology (Replaced by Robot!?, 2018). Creativity, critical thinking, and the ability to build trusted relationships with stakeholders are declared as key competences for human practitioners that separate them from machines (Galloway and Swiatek, 2018; Niederhäuser and Rosenberger, 2018).

But despite the named possibilities, only very few organisations seem to have adopted $\mathrm{Al}$ in their communication departments. A recent study among Chief Communication Officers in Switzerland revealed that just three percent of their organisations use Al technologies in communications (Niederhäuser and Rosenberger, 2018).

There seem to be significant challenges and hurdles hindering communication professionals from implementing Al that need further investigation. According to the Technology-Organisation-Environment (TOE) framework, the adoption of technological innovations in organisations depends on their characteristics and resources (e. g., structures and communication processes), but also on their environment (e. g., technological infrastructure and governmental regulations) (DePietro et al., 1990). Obstacles for bringing Al to communications might be found on the meso level of organisations, departments, and agencies, as well as on the macro level of society (see figure 1). None of these variables and drivers have been researched until now. While assessing all of them would be desirable, achieving first insights into some of these aspects is also a worthwhile endeavour. 
Figure 1. The Technology-Organisation-Environment (TOE) framework.

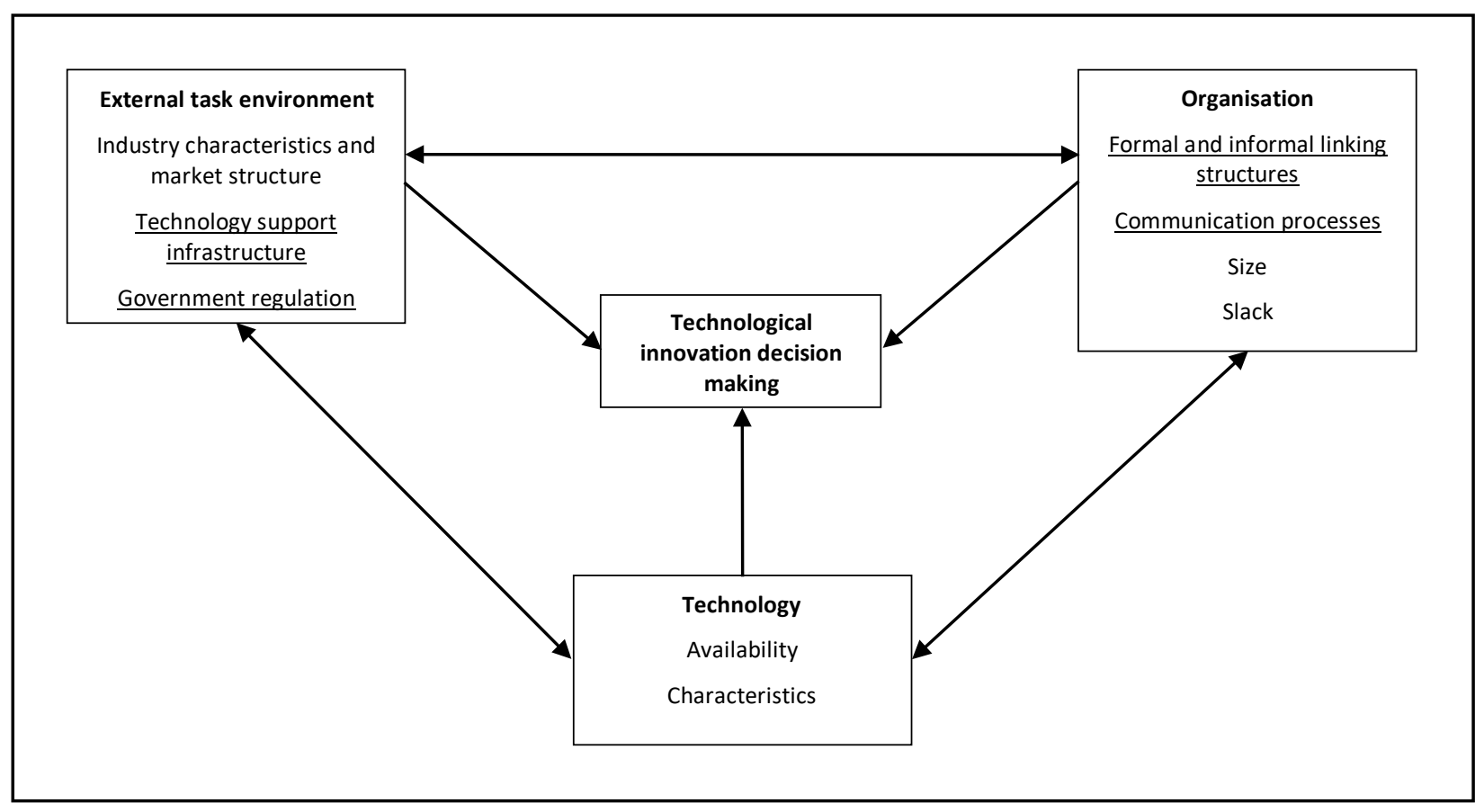

Note. Figure derived from Baker (2011). Constructs that were assessed in this study are underlined.

Furthermore, it is not known whether practitioners share the optimistic view that industry magazines and practitioner literature shed on artificial intelligence - or whether they fear that Al will overtake many tasks done by themselves, resulting in shrinking salaries, rising unemployment, and destruction of professional identity (Makridakis, 2017; Tredinnick, 2017). The implementation of a new technology may involve risks for organisations and their members. Sherer and Alter (2004) compiled several hundred risk factors for information systems projects. More specifically, Baccarini et al. (2004) name several risks in managing information technology projects on an individual level, including "lack of ability, training, motivation and experience of staff" (p. 287). Floridi et al. (2018) argue that Al has the potential to devalue human skills, remove human responsibilities, reduce human control, and erode human self-determination. This may especially affect less-skilled employees, as pointed out by Kellogg, Valentine and Christin (in press). Practitioners might anticipate these risks, and thus observe the advent of artificial intelligence in communications with caution.

Ultimately, the perception of $\mathrm{Al}$ and conclusions for the communications profession depend on the understanding of the concept. It can be estimated that the lack of experience and the lack of scholarly literature in the field has not led to consistent and concise knowledge levels among practitioners. It will be necessary to explore this baseline and potential differences related to the personal or organisational background of practitioners and their usage of artificial intelligence devices (e.g. smartphone applications, smart speakers). Theories of technology adoption in organisations highlight differences between employees of various gender, age, and experience. For example, the Unified Theory of Acceptance and Use of Technology (UTAUT) and its successor, the UTAUT2, incorporate these variables as moderators in the relationship between different determinants and the acceptance and usage of new information systems (Venkatesh et al., 2003; Venkatesh et al., 2012). We therefore expect the perception of Al to vary between women and men, younger and older professionals, and between those who have already adopted to Al devices versus 
those who have not. Furthermore, the TOE framework (DePietro et al., 1990) points to the assumption that the perception of $\mathrm{Al}$ in communication management may differ across different types of organisations.

\section{Research questions}

Considering these research gaps, Waxman (2018) calls for a "more scientific approach what [the future PR's] role might be" and "how automation, and shifts in the job market might affect employee motivation and morale" (pp. 14-15) in the discipline. We aim to address these issues and investigate the perspective(s) of communication professionals, by addressing the following research questions:

\section{RQ1: How much do professionals know about Al and to what extent are they already using Al technologies in their everyday lives? \\ RQ2: How do professionals rate the impact of Al on communication management? \\ RQ3: Which challenges do professionals identify for implementing Al in communication management?}

RQ4: Which risks do they perceive?

\section{Methodology}

The research questions were addressed as part of a more comprehensive, quantitative crossnational online survey among communication professionals in Europe. The sample included 2,689 practitioners, with a majority having more than ten years of experience in communications and working in leading positions.

\section{Instrument}

The survey contained six questions covering artificial intelligence. Items for each question were derived from the literature discussed above to construct a research instrument tailored for our needs. Additional questions from the overall survey covering demographic variables were also evaluated for this research.

To draw participants into the topic, we first asked them to rate the impact that $\mathrm{Al}$ will have on the profession, the department or agency they work in, and the way they personally work (micro / meso / macro perspective), using a 5-point Likert scale ranging from $1=$ "very low impact" to $5=$ "very high impact". Expertise on Al was assessed via a definitional question: We presented eight characteristics of Al (four correct and four wrong ones according to the definition developed above) and asked respondents to pick those which they think are appropriate. The correct definition was presented afterwards to remove any eventual knowledge difference bias. We then asked for perceived difficulties in securing requirements for using $\mathrm{Al}$ in communications with two items on the individual level (competencies / motivation of practitioners), two items on the level of organisations (organisational infrastructure / support by top management, leaders, and clients), and two items on the macro level of societies (societal infrastructure / acceptance by users and external stakeholders). The first item on each level referred to structural and the second to cognitive or motivational aspects. Every item was rated on a 5-point Likert scale from $1=$ 
"not likely" to 5 = "very likely". The same approach was used to investigate perceived risks, with again two items addressing the micro level (communication practitioners will lose their jobs / will receive shrinking salaries), the meso level (organisations will struggle with varied staff competence / with unclear responsibilities), and the macro level (the communications profession will lose its core competences / will lose its identity), assessed via a 5-point Likert scale from 1 = "not likely" to 5 = "very likely". Last but not least, we asked professionals whether they use Al assistants on their smartphones (e. g., Apple Siri, Google Assistant), and Al devices in their homes or offices (e. g., Amazon Echo with Alexa, Apple HomePod, Google Home). Independent variables that were gathered include gender, age, and nationality of the respondents, as well as the type of organisation and hierarchical position they work in.

The questionnaire was pretested among 67 communication practitioners in 20 European countries. All amendments were taken into account when finalising the instrument.

\section{Sample}

The survey was online for five weeks in February and March 2019. A large number of professionals working in communication departments of all kinds of organisations and in communication agencies and consultancies across all 50 European countries were invited with personalised e-mails based on a database provided by a large professional association.

In total, 2,883 respondents completed the survey. Those who could not be analysed as part of the population - for example, scholars, students, and practitioners from other regions - were excluded, which resulted in 2,689 responses used for data analysis. $56.8 \%$ of all participants were female $(N=1,523)$ and $43.2 \%$ were male $(N=1,158)$. Their average age was 42.7 years. The majority had an academic degree $(95.9 \%, N=2,570)$, with $63.2 \%$ holding a masters / postgraduate degree $(N=1,695)$ and $8.2 \%$ a doctorate $(N=221)$. $67.8 \%(N=1,819)$ of the respondents had more than ten years of experience in communications and $67.6 \%(N=1,820)$ were in leading positions as either head of communication / agency CEO or unit / team leader. Seven out of ten professionals worked in communication departments of joint stock companies $(19.9 \%, N=534)$, private companies (23.1\%, $N=621)$, governmental organisations $(16.6 \%, N=447)$, or non-profit organisations $(10.8 \%, N=290)$; the others in communication consultancies, PR agencies, or as freelance consultants $(29.6 \%, N=797)$. As for their areas of work, overall communication $(38.2 \%, N=$ $1,027)$, strategy and coordination $(31.7 \%, N=852)$, media relations/press spokesperson (30.9\%, $N=830)$, online communication/social media $(26.2 \%, N=705)$, and marketing/brand/consumer communication $(24.7 \%, N=665)$ were the most frequently mentioned subdisciplines of communication management (three answers possible on a list of overall 19). Most respondents were based in Southern Europe $(31.4 \%, N=845)$ and Western Europe $(29.0 \%, N=781)$, followed by Northern Europe $(22.6 \%, N=609)$ and Eastern Europe $(16.9 \%, N=454)$.

\section{Analyses}

Data was analysed using the Statistical Package for the Social Sciences (SPSS). Depending on the type of variable, significant differences and (inter-)dependencies were revealed using Pearson's chi-square test, one-way ANOVA with post-hoc Scheffé, Pearson product-moment correlation, and Kendall rank correlation.

\section{Findings}


Overall, communication professionals reveal a rather limited understanding of artificial intelligence. They expect greater impact on the profession as a whole than on the way their organisation or themselves work. Lack of individual competencies, and organisations struggling with both different levels of competency and unclear responsibilities are identified as key challenges and risks. The perception of artificial intelligence in communication management is shaped by gender, age, hierarchical position, and Al adoption of the participants.

Adoption and expertise of communication professionals on $A$ ( $(R Q 1)$

$13.3 \%$ of the respondents can be identified as Al adopters, that means, they are using both intelligent assistants on their smartphones and intelligent devices in their home or office. $15.4 \%$ of the surveyed professionals were able to classify seven or all eight of the proposed characteristics of Al correctly as either right or wrong, and can therefore be considered as "Al experts" (see Table 1). The vast majority, however, has a rather vague understanding of artificial intelligence, and $7.1 \%$ - the "Al greenhorns" - skipped the definitional question by stating that they don't know this at all. There are more male Al experts (18.3\%) than female (13.3\%). Al adoption and expertise are not linked - surprisingly, we found more Al experts among those who don't use the technology in their everyday lives yet (15.7\% versus $13.7 \%)$. 
Table 1. How communication professionals define Al.

\begin{tabular}{lc}
\hline Decisions and actions by software-driven agents & $76.1 \%$ \\
Learning from experience & $58.6 \%$ \\
(Computer-assisted activities by humans) & $54.8 \%$ \\
Adapting to changing goals and unpredictable situations & $35.7 \%$ \\
Processing natural language & $34.6 \%$ \\
(Understanding emotions) & $15.5 \%$ \\
(Owning all human abilities) & $10.7 \%$ \\
(Experiencing feelings) & $6.6 \%$ \\
\hline
\end{tabular}

Note. Wrong (incorrect) definitions appear in parentheses. $N=2,498$ communication professionals in Europe. Percentages: Frequency based on selection. Q: The term "Artificial Intelligence" is characterised in various ways. Please pick all definitions which you think are appropriate. Artificial Intelligence refers to ... Al Experts: $15.4 \%$ of the overall sample and $16.6 \%$ of those who have selected definitions. The largest portion $(38.6 \%)$ has classified 5 of 8 items correctly.

\section{Impact of $A$ I on communication management (RQ2)}

Three out of four communication professionals believe that artificial intelligence will change the profession of public relations and communications as a whole $(M=3.40, S D=1.17, N=$ $2,566)$. Every second respondent $(50.6 \%)$ states that the impact on the profession will be high or even very high. Interestingly, the perception of impact on the meso and micro level is quite different: Only $37.2 \%$ of the professionals anticipate substantial changes to the way their communication department or agency works $(M=3.05, S D=1.19)$, and even less (33.9\%) believe that Al will significantly change the way they personally work $(M=2.93, S D=$ 1.20).

Significant differences were revealed across various types of organisations and hierarchical levels of the respondents. Professionals working in joint stock companies estimate stronger impact on the organisational and personal level than practitioners in other types of organisations ( $40.3 \%$ high or very high impact on the meso level; $37.1 \%$ high or very high impact on the micro level). The same goes for communication leaders compared to their peers on lower (job position or employment) ranks. The expected Al impact reflects the organisational hierarchy, with top leaders stating the highest and team members the lowest effects across the macro, meso, and micro levels (see Table 2).

Table 2. Perceived impact of Al on communications among communication professionals.

\begin{tabular}{lcccc}
\hline $\begin{array}{l}\text { Artificial intelligence will have } \\
\text { impact on... }\end{array}$ & $\begin{array}{c}\text { Head of } \\
\text { communication } \\
\text { department } \\
\text { Agency CEO }\end{array}$ & $\begin{array}{c}\text { Unit leader / } \\
\text { Team leader }\end{array}$ & $\begin{array}{c}\text { Team } \\
\text { member / } \\
\text { Consultant }\end{array}$ & Overall \\
\hline The profession of public relations & 3.46 & 3.33 & 3.33 & 3.39 \\
and communications as a whole * & $(1.14)$ & $(1.18)$ & $(1.18)$ & $(1.16)$ \\
The way our department / & 3.11 & 3.02 & 2.94 & 3.03 \\
agency works ** & $(1.18)$ & $(1.17)$ & $(1.22)$ & $(1.19)$ \\
The way I personally work * & 2.97 & 2.91 & 2.85 & 2.92 \\
\hline
\end{tabular}

Note. Standard deviations appear in parentheses below the means. $N=2,566$ communication professionals in Europe. Q: Artificial Intelligence is becoming part of everyday life, for example in language-based assistants (Apple Siri, Amazon Alexa) and algorithms used on news sites and e-commerce platforms. This might also impact communications. In your opinion, how much impact will Artificial Intelligence have on ... 5-point Likert scale ranging from $1=$ "Very low impact" to $5=$ "Very high impact". * Significant at the $p \leq 0.05$ level based on Kendall rank correlation. ${ }^{* *}$ Highly significant at the $p \leq 0.01$ level based on Kendall rank correlation. 
Competencies of communication practitioners $(M=3.58, S D=1.04, N=2,566)$ and organisational infrastructure (e. g., IT, budgets, responsibilities) $(M=3.54, S D=1.15$ ) were identified as key challenges for implementing artificial intelligence in communication management with more than every second respondent finding them difficult or even very difficult to secure. They are followed by acceptance by users and external stakeholders $(M=$ 3.43, $S D=1.02)$, motivation of communication practitioners to use $\mathrm{Al}(M=3.29, S D=1.12)$, and support by top management, leaders and clients $(M=3.25, S D=1.12)$. Societal infrastructure (e. g., highspeed internet, legal rules) is seldom recognised as a hurdle $(M=$ $2.99, S D=1.18$ ). Challenges on the organisational level pose a problem especially for nonprofit organisations. They rank significantly higher on the items organisational infrastructure $(F=(4 ; 2561)=4.808 ; p<0.01)$, and support by top management, leaders, and clients $(F=(4$; $2,561)=3.666 ; p<0.01$ ) (see Table 3). Other than that, it's noteworthy that Al adopters see overall less challenges (index value 3.21 ) than those who are not frequently using Al yet (index value 3.37). 
Table 3. Perceived challenges of bringing Al to communications across different types of organisations.

\begin{tabular}{|c|c|c|c|c|c|c|}
\hline & $\begin{array}{l}\text { Joint stock } \\
\text { companies }\end{array}$ & $\begin{array}{c}\text { Private } \\
\text { companies }\end{array}$ & $\begin{array}{c}\text { Governmental } \\
\text { organisations }\end{array}$ & $\begin{array}{c}\text { Non-profit } \\
\text { organisations }\end{array}$ & $\begin{array}{c}\text { Consultancies } \\
\& \text { agencies }\end{array}$ & Overall \\
\hline $\begin{array}{l}\text { Competencies } \\
\text { of communication } \\
\text { practitioners to use Al }\end{array}$ & $\begin{array}{c}3.61 \\
(1.03)\end{array}$ & $\begin{array}{c}3.50 \\
(1.04)\end{array}$ & $\begin{array}{c}3.61 \\
(1.00)\end{array}$ & $\begin{array}{c}3.60 \\
(0.96)\end{array}$ & $\begin{array}{c}3.59 \\
(1.08)\end{array}$ & $\begin{array}{c}3.58 \\
(1.04)\end{array}$ \\
\hline $\begin{array}{l}\text { Motivation } \\
\text { of communication } \\
\text { practitioners to use } \mathrm{Al}\end{array}$ & $\begin{array}{c}3.27 \\
(1.13)\end{array}$ & $\begin{array}{c}3.19 \\
(1.13)\end{array}$ & $\begin{array}{c}3.33 \\
(1.09)\end{array}$ & $\begin{array}{c}3.33 \\
(1.06)\end{array}$ & $\begin{array}{c}3.36 \\
(1.15)\end{array}$ & $\begin{array}{c}3.29 \\
(1.12)\end{array}$ \\
\hline $\begin{array}{l}\text { Organisational } \\
\text { infrastructure } \\
\text { (e.g. IT, budgets, } \\
\text { responsibilities) ** }\end{array}$ & $\begin{array}{c}3.46 \\
(1.22)\end{array}$ & $\begin{array}{c}3.50 \\
(1.14)\end{array}$ & $\begin{array}{c}3.66 \\
(1.10)\end{array}$ & $\begin{array}{c}3.76 \\
(1.08)\end{array}$ & $\begin{array}{c}3.49 \\
(1.17)\end{array}$ & $\begin{array}{c}3.54 \\
(1.15)\end{array}$ \\
\hline $\begin{array}{l}\text { Support by top } \\
\text { management, } \\
\text { leaders, and } \\
\text { clients ** }\end{array}$ & $\begin{array}{c}3.13 \\
(1.15)\end{array}$ & $\begin{array}{c}3.22 \\
(1.11)\end{array}$ & $\begin{array}{c}3.31 \\
(1.13)\end{array}$ & $\begin{array}{c}3.43 \\
(1.06)\end{array}$ & $\begin{array}{c}3.27 \\
(1.12)\end{array}$ & $\begin{array}{c}3.25 \\
(1.12)\end{array}$ \\
\hline $\begin{array}{l}\text { Societal } \\
\text { infrastructure } \\
\text { (e.g. high-speed } \\
\text { internet, legal rules) }\end{array}$ & $\begin{array}{c}3.04 \\
(1.20)\end{array}$ & $\begin{array}{c}2.93 \\
(1.17)\end{array}$ & $\begin{array}{c}3.03 \\
(1.15)\end{array}$ & $\begin{array}{c}3.04 \\
(1.15)\end{array}$ & $\begin{array}{c}2.97 \\
(1.21)\end{array}$ & $\begin{array}{c}2.99 \\
(1.18)\end{array}$ \\
\hline $\begin{array}{l}\text { Acceptance by } \\
\text { users and external } \\
\text { stakeholders }\end{array}$ & $\begin{array}{c}3.46 \\
(1.03)\end{array}$ & $\begin{array}{c}3.38 \\
(1.02)\end{array}$ & $\begin{array}{c}3.48 \\
(1.02)\end{array}$ & $\begin{array}{c}3.49 \\
(0.96)\end{array}$ & $\begin{array}{c}3.40 \\
(1.04)\end{array}$ & $\begin{array}{c}3.43 \\
(1.02)\end{array}$ \\
\hline
\end{tabular}

Note. Standard deviations appear in parentheses below the means. $N=2,566$ communication professionals in Europe. Q: Artificial Intelligence (AI) can be described as flexible decision-making processes and actions of software-driven agents. They adapt to changing goals and unpredictable situations, learn from experience, and are based on technologies like natural language processing, data retrieval and knowledge representation, semantic reasoning, and machine learning. Taking this definition into account and thinking of your organisation, how difficult is it to secure the following requirements for using Al in communications? 5-point Likert scale ranging from $1=$ "Not difficult" to $5=$ "Very difficult". ** Highly significant at the $p \leq 0.01$ level based on Scheffé post-hoc test.

\section{Risks of bringing Al to communication management (RQ4)}

Organisations struggling with varied staff competence $(M=3.44, S D=1.13, N=2,566)$ and unclear responsibilities $(M=3.14, S D=1.22)$ are the major concerns for bringing artificial intelligence to communications; other risks on the macro level of the profession - loss of identity $(M=2.39, S D=1.25)$, and loss of core competences $(M=2.29, S D=1.20)-$, or on the micro level of individual practitioners - shrinking salaries $(M=2.44, S D=1.18)$, and loss of jobs $(M=2.34, S D=1.20)$ - are identified by only every fifth respondent. Remarkably, it is especially the younger generation, i.e. professionals in their 20s, that identify these issues as possible risks (see Table 4). Professionals working in non-profit organisations are particularly aware of risks at the organisational level (61.5\% expecting struggles with varied staff competence, $46.9 \%$ expecting struggles with unclear responsibilities), and top communicators (index value 2.60) have a more optimistic view than team leaders (index value 2.67 ) and team members (index value 2.75 ). The latter insight might reflect differences in job descriptions: leaders spend more time on managing activities like planning and evaluating that can be supported by Al technologies. Hands-on and routine activities like writing and translating news pieces or providing feedback to stakeholders, however, might become obsolete in the age of data-driven communication. 
Table 4. Perceived risks of bringing Al to communication management across generations.

\begin{tabular}{lcccccc}
\hline & $\begin{array}{c}29 \text { or } \\
\text { younger }\end{array}$ & $30-39$ & $40-49$ & $50-59$ & $\begin{array}{c}60 \text { or } \\
\text { older }\end{array}$ & Overall \\
\hline Communication practitioners & 2.65 & 2.16 & 2.33 & 2.43 & 2.33 & 2.34 \\
will lose their jobs ** & $(1.33)$ & $(1.16)$ & $(1.15)$ & $(1.20)$ & $(1.22)$ & $(1.20)$ \\
Communication practitioners & 2.82 & 2.29 & 2.43 & 2.48 & 2.32 & 2.44 \\
will receive shrinking salaries & $(1.30)$ & $(1.14)$ & $(1.15)$ & $(1.13)$ & $(1.24)$ & $(1.18)$ \\
Organisations will struggle & 3.37 & 3.38 & 3.51 & 3.43 & 3.41 & 3.44 \\
with varied staff competence & $(1.09)$ & $(1.15)$ & $(1.13)$ & $(1.11)$ & $(1.21)$ & $(1.13)$ \\
Organisations will struggle & 3.15 & 3.08 & 3.15 & 3.18 & 3.19 & 3.14 \\
with unclear responsibilities & $(1.24)$ & $(1.21)$ & $(1.23)$ & $(1.19)$ & $(1.31)$ & $(1.22)$ \\
The communications profession & 2.63 & 2.17 & 2.29 & 2.28 & 2.17 & 2.29 \\
will lose its core competences $* *$ & $(1.26)$ & $(1.14)$ & $(1.19)$ & $(1.20)$ & $(1.30)$ & $(1.20)$ \\
The communications profession & 2.81 & 2.32 & 2.36 & 2.33 & 2.27 & 2.39 \\
will lose its identity ** & $(1.37)$ & $(1.23)$ & $(1.21)$ & $(1.22)$ & $(1.31)$ & $(1.25)$ \\
\hline
\end{tabular}

Note. Standard deviations appear in parentheses below the means. $N=2,566$ communication professionals in Europe. Q: What could be possible risks that Artificial Intelligence brings to communications? 5-point Likert scale ranging from $1=$ "Not likely" to $5=$ "Very likely". ** Highly significant at the $p \leq 0.01$ level based on Pearson correlation.

Indices of all items on impact and of all items on risks were used to cluster respondents. Generally speaking, the profession has a rather optimistic view: seven out of ten practitioners (69.7\%) expect impact to a greater or lesser extent, but score low or neutral on the risk scale (risk index value $\leq 3$ ). However, there is a relatively small proportion of $14.7 \%$ Al pessimists that anticipate both strong impact and many risks (both indices $>3$ ).

\section{Discussion}

Is artificial intelligence a technology that has yet to be fully understood and adopted in communication management practice? Our empirical study found a broad consensus among practitioners that Al will change the profession. When asking for the perceived impact in detail, however, we obtained a cognitive bias similar to the third-person-effect of media influence (Davison, 1983): practitioners expect major changes induced by Al to the profession - but not so much in their own organisation, and even less to them personally. This may also indicate that professionals have followed the debate in industry magazines, but have not witnessed (or know about) any application of Al in their own organisation, department or agency, or in their personal everyday use. The same goes somehow for academia: the rising interest of the scientific community in Al has not reached the communication management discipline yet. Our study, being the first quantitative study in the field, was a first attempt to put artificial intelligence on the agenda of marketing and public relations research. Two insights might be particularly relevant for the profession: communicators need to get familiar with artificial intelligence; and communication leaders should recognise their responsibility for implementing Al into their department or agency.

\section{Need for self-education}

Despite the current hype about artificial intelligence and its frequent coverage in industry magazines, most communication professionals' expertise on the technology is rather sketchy. This finding is similar to and in line with findings about the limited knowledge communication practitioners have about big data, a technology that is linked to $\mathrm{Al}$ (Wiesenberg et al., 2017). More than that, the adoption of Al based devices in everyday life does not lead to expertise, so 'learning by doing' approaches should be assessed with 
caution. Preferably, practitioners should educate themselves systematically on new technologies, as pointed out by Galloway and Swiatek (2018). The latter becomes especially important, as the personal competencies of professionals are identified as the key challenge for bringing Al to communication management, and different levels of it as a major risk source for organisations. Al might not be able to mimic every asset of a human communicator, but that does not free practitioners from becoming "master of the data" (Rosenberger and Niederhäuser, 2018, p. 4; translated by the authors). With the main challenges identified on the individual and organisational level, the good news is that societal prerequisites seem to be secured. Communication professionals are not especially concerned about the acceptance by external stakeholders, and even less on securing highspeed internet or legal rules as the backbones of implementing Al.

\section{Implementing Al as a leadership issue}

Not every practitioner follows Wirth's (2018) optimistic claim that it is "time to embrace Al" (p. 438). On the other hand, the majority of respondents in our survey was not overly sceptical regarding $\mathrm{Al}$, as suggested by Waxman (2018). It might be a core task for communication leaders, who are the ones that anticipate the strongest impact of Al on the profession (but the least risks), to prepare their fellows, and to integrate peers with different levels of knowledge on artificial intelligence and various reservations against it. Two critical groups might be those who expect high impacts and many risks - 15 percent in the sample of our study -, and the younger professionals in their 20s. Ironically, this generation of socalled "digital natives" (Prensky, 2001) revealed the strongest concerns against artificial intelligence. Most anticipated risks were those on the organisational level, namely struggles with varied staff competence and unclear responsibilities. This again highlights the crucial role of communication leaders who are in charge of staffing proper teams, and planning Al related tasks thoughtfully. Leadership, i.e. top management support and presence of a project champion, becomes a key factor for technology adoption in organisations (Aziz and Yusof, 2012; Pare et al., 2011).

\section{Limitations and implications for future research on $\mathrm{Al}$ in communication management}

Several aspects should be taken into consideration when evaluating the results of our study. Since the total population of communication professional in Europe is unknown, and the response rate from practitioners in Eastern Europe was rather low, our sample cannot be comprehended as a statistically accurate representation of the profession. The chosen method only allowed us to assess perceptions of communication professionals. Their impression of challenges and risks might be biased by their concept of Al (although we tried to counteract this by incorporating our definition into the questionnaire), or by other confounding variables that we did not measure. Also, we did not ask participants whether $\mathrm{Al}$ is already used in their communication department or agency, and if yes, to what extent, as we expected a considerable amount of respondents would not be able to answer this. The theoretical models of technology adoption we referred to in the literature review are complex, and contain constructs and dependencies that we were not able to assess.

Overall, the scope of our work was to present some initial insights on the advent of $\mathrm{Al}$ in communication management. Thus, it might be an opportunity for future research to dig deeper both theoretically and empirically by broadening the perspective on possible challenges and risks, incorporating more variables, and linking them with data on the actual 
use of the technology. Our findings and the developed instruments might serve as a solid starting point for these further investigations.

\section{References}

Aziz, K. and Yusof, M. M. (2012), "Measuring organizational readiness in information systems adoption", Paper presented at the Eighteenth Americas Conference on Information Systems (AMCIS), August 9-12, Seattle, Washington, available at: https://pdfs.semanticscholar.org/6299/7c5708fb62869fcac108966c8e649777e24a.p df (accessed 18 January 2020).

Baccarini, D., Salm, G. and Love, P. E. D. (2004), "Management of risks in information technology projects", Industrial Management \& Data Systems, Vol. 104 No. 4, pp. 286-295.

Baker, J. (2011), "The Technology-Organization-Environment framework", in Dwivedi, Y. K., Wade, M. R. and Schneberger, S. L. (Eds.), Information systems theory: Explaining and predicting our digital society, Vol. 1, Springer, New York, NY, pp. 231-245.

Brønn, P. S. (2014), “Communication management”, in Donsbach, W. (Ed.), The international encyclopedia of communication, John Wiley \& Sons, Hoboken, NJ, pp. 753-757.

Collister, S. (2016). "Algorithmic Public Relations: Materiality, technology and power in a post-hegemonic world", in L'Etang, J., McKie, D., Snow, N. and Xifra, J. (Eds.), The Routledge handbook of critical public relations. Routledge, London, UK, pp. 360-371.

Davison, W. P. (1983), "The third-person-effect in communication", Public Opinion Quarterly, Vol. 47 No. 1, pp. 1-15.

Dawar, N. and Bendle, N. (2018), "Marketing in the age of Alexa", Harvard Business Review, Vol. 96 No. 3, pp. 81-86.

DePietro, R., Wiarda, E. and Fleischer, M. (1990), "The context for change: Organization, technology and environment", in Tornatzky, L. G. and Fleischer, M. (Eds.), The processes of technological innovation, Lexington Books, Lexington, MA, pp. 151-175.

Dimitrieska, S., Stankovska, A. and Efremova, T. (2018), "Artificial intelligence and marketing", Entrepreneurship, Vol. 7 No. 2, pp. 298-304.

Floridi, L., Cowls, J., Beltrametti, M., Chatila, R., Chazerand, P., Dignum, V., Luetge, C., Madelin, R., Pagallo, U., Rossi, F., Schafer, B., Valcke, P. and Vayena, E. (2018), "Al4People - An ethical framework for a good Al society: Opportunities, risks, principles, and recommendations", Minds and Machines, Vol. 28 No. 4, pp. 689-707.

Foldes, S. (2018), "Al won't take over corporate communications, but it can help", available at: https://www.forbes.com/sites/forbesagencycouncil/2018/03/02/ai-wont-takeover-corporate-communications-but-it-can-help/\#4a6dabf47aa0 (accessed 18 January 2020).

Galloway, C. and Swiatek, L. (2018), "Public relations and artificial intelligence: It's not (just) about robots", Public Relations Review, Vol. 44 No. 5, pp. 734-740.

Gentsch, P. (2019), Al in marketing, sales and service: How marketers without a data science degree can use $\mathrm{Al}$, big data and bots, Palgrave Macmillan, Cham, $\mathrm{CH}$.

Jordan, M. (2018), "The Role of Artificial Intelligence in Financial Reporting", Working paper, USC Annenberg Center for Public Relations, Los Angeles, CA.

Kaplan, A. and Haenlein, M. (2019), "Siri, Siri, in my hand: Who's the fairest in the land? On the interpretations, illustrations, and implications of artificial intelligence", Business Horizons, Vol. 62 No. 1, pp. 15-25.

Kellogg, K. C., Valentine, M. and Christin, A. (2020), "Algorithms at work: The new contested terrain of control", Academy of Management Annals, Vol. 14 No. 1, pp. 366-410. 
King, K. (2019), Using artificial intelligence in marketing: How to harness Al and maintain the competitive edge, Kogan Page, New York, NY.

Kose, U. and Sert, S. (2017), "Improving content marketing processes with the approaches by artificial intelligence", Ecoforum, Vol. 6 No. 1.

Makridakis, S. (2017), "The forthcoming artificial intelligence revolution: Its impact on society and firms", Working paper, Neapolis University, Paphos, GR.

Niederhäuser, M. and Rosenberger, N. (2018), "Kommunikation in der digitalen Transformation: Bestandsaufnahme und Entwicklungsbedarf des strategischen Kommunikationsmanagements von Wirtschaftsunternehmen, Verwaltungen und Non-Profit-Organisationen in der Schweiz", Working paper, ZHAW Zürcher Hochschule für Angewandte Wissenschaften, Winterthur, $\mathrm{CH}$.

Nilsson, N. J. (1998), Artificial intelligence: A new synthesis, Morgan Kaufmann, San Francisco, CA.

Pare, G., Sicotte, C., Poba-Nzaou, P. and Balouzakis, G. (2011), “Clinicians' perceptions of organizational readiness for change in the context of clinical information system projects: Insights from two cross-sectional surveys", Implementation Science, Vol. 6 No. 1, p. 15.

Penn, C. S. (2017), Al for marketers: An introduction and primer, Trust Insights, Norfolk, MA.

Petrucci, A. (2018), "How artificial intelligence will impact corporate communications", available at:

https://www.forbes.com/sites/forbescommunicationscouncil/2018/04/20/howartificial-intelligence-will-impact-corporate-communications/\#2f69b54b1dc6 (accessed 18 January 2020).

Poole, D. L. and Mackworth, A. K. (2017), Artificial intelligence: Foundations of computational agents, Oxford University Press, New York, NY.

Pradeep, A. K., Appel, A. and Sthanunathan, S. (2019), Al for marketing and product innovation: Powerful new tools for predicting trends, connecting with customers, and closing sales, John Wiley \& Sons, Hoboken, NJ.

Prensky, M. (2001), "Digital natives, digital immigrants", On The Horizon, Vol. 9 No. 5, pp. 16.

Rahwan, I., Cebrian, M., Obradovich, N., Bongard, J., Bonnefon, J.-F., Breazeal, C., Crandall, J. W., Christakis, N. A., Couzin, I. D., Jackson, M. O., Jennings, N. R., Kamar, E., Kloumann, I. M., Larochelle, H., Lazer, D., McElreath, R., Mislove, A., Parkes, D. C., Pentland, A. S., Roberts, M. E., Shariff, A., Tenenbaum, J. B. and Wellman, M. (2019), "Machine behaviour", Nature, Vol. 568 No. 7753, pp. 477-486.

Replaced by Robot!? (2018), "Will robots take my job?", available at: https://www.replacedbyrobot.info (accessed 18 January 2020).

Rosenberger, N. and Niederhäuser, M. (2018), "Technologisches Verständnis wird zur neuen Schlüsselkompetenz", The Reporting Times, No. 13, p. 4.

Russell, S. J. and Norvig, P. (2016), Artificial intelligence: A modern approach, Pearson Education, Harlow, UK.

Schweyer, A. (2018), "Predictive analytics and artificial intelligence in people management", Working Paper, Incentive Research Foundation, McLean, VA.

Seligman, J. (2019), Artificial intelligence and marketing, Taylor \& Francis, London, UK.

Sherer, S. A. and Alter, S. (2004), "Information system risk and risk factors: Are they mostly about information systems?", Communications of the Association for Information Systems, Vol. 14, pp. 29-64. 
Shoham, Y., Perrault, R., Brynjolfsson, E., Clark, J., Manyika, J., Niebles, J. C., Lyons, T., Etchemendy, J., Grosz, B. and Bauer, Z. (2018), "The Al index 2018 annual report", Working paper, Stanford University, Stanford, CA.

Sterne, J. (2017), Artificial intelligence for marketing: Practical applications, John Wiley \& Sons, New York, NY.

Struhl, S. (2017), Artificial intelligence marketing and predicting consumer choice: An overview of tools and techniques, Kogan Page, London, UK.

Tredinnick, L. (2017), "Artificial intelligence and professional roles", Business Information Review, Vol. 34 No. 1, pp. 37-41.

Valin, J. (2018), "Humans still needed: An analysis of skills and tools in public relations", Working paper, Chartered Institute of Public Relations, London, UK.

Venkatesh, V., Morris, M. G., Davis, G. B. and Davis, F. D. (2003), "User acceptance of information technology: Toward a unified view", MIS Quarterly, Vol. 27 No. 3, pp. 425-478.

Venkatesh, V., Thong, J. Y. L. and Xu, X. (2012), "Consumer acceptance and use of information technology: Extending the unified theory of acceptance and use of technology", MIS Quarterly, Vol. 36 No. 1, pp. 157-178.

Waxman, M. (2018), "Putting the Al in PR: Examining how artificial intelligence could impact communications and public relations", Unpublished thesis, McMaster University, Department of Communications Studies and Multimedia, Hamilton, CA.

Wiesenberg, M. and Tench, R. (2020, in press). "Deep strategic mediatization: Organizational leaders' knowledge and usage of social bots in an era of disinformation", International Journal of Information Management. https://doi.org/10.1016/j.ijinfomgt.2019.102042

Wiesenberg, M., Zerfass, A. and Moreno, A. (2017), "Big Data and automation in strategic communication", International Journal of Strategic Communication, Vol. 11 No. 2, pp. 95-114.

Wirth, N. (2018), "Hello marketing, what can artificial intelligence help you with?", International Journal of Market Research, Vol. 60 No. 5, pp. 435-438.

Young, M. (2018), "Discovering the children of Al: Machine learning \& deep learning", available at: https://www.functionize.com/blog/discovering-the-children-of-aimachine-learning-deep-learning (accessed 18 January 2020). 